Morgado, José Carlos; Santos, Júlio; Silva, Rui da - Currículo, memória e fragilidades:

contributos para (re)pensar a educação na Guiné-Bissau. Configurações, vol. 17, 2016, pp. 57-77

\title{
Currículo, memória e fragilidades: contributos para (re)pensar a educação na Guiné-Bissau
}

\author{
JOSÉ CARLOS MORGADO* \\ Universidade do Minho \\ JÚLIO SANTOS** \\ Centro de Recursos para a Cooperação e Desenvolvimento, Universidade do Minho \\ RUI DA SILVA*** \\ Instituto de Educação, Universidade do Minho
}

\section{Resumo}

O artigo procura, de forma exploratória, compreender se e como as questões da memória estão presentes na construção do currículo num pequeno Estado frágil e periférico do sistema mundial, especificamente a Guiné-Bissau. A análise centra-se no domínio macro (político-administrativo) de decisão curricular, isto é, nas decisões curriculares ao nível político-administrativo, e procura deslindar algumas nuances que condicionam esse processo.

A reflexão realizada permite inferir que, devido à condição periférica e dependente de ajuda externa, a Guiné-Bissau tem dificuldade em liderar a construção do seu currículo de forma independente e autónoma. De facto, tem vindo a verificar-se que, na maioria dos casos, a construção do currículo é um processo externo, tendo por base reformas viajantes que, muitas vezes, não se sabe de onde vêm e para onde se destinam. A análise permitiu, ainda, constatar que neste empreendimento a memória parece estar a ser utilizada mais com o intuito de legitimar uma determinada opção do que para reforçar e/ ou consolidar a(s) sua(s) identidade(s).

Palavras-chave: currículo, memória, fragilidade, transnacionalização da educação, periferia(s).

\footnotetext{
* Professor Associado no Instituto de Educação da Universidade do Minho, Diretor do Departamento de Estudos Curriculares e Tecnologia Educativa e Investigador integrado no Centro de Investigação em Educação (CIEd). Email: jmorgado@ie.uminho.pt.

* Professor Auxiliar Convidado e Coordenador do Centro de Recursos para a Cooperação e Desenvolvimento no Instituto de Educação da Universidade do Minho. Email: jpsantos@ie.uminho.pt. *** Bolseiro de investigação no Instituto de Educação da Universidade do Minho a desenvolver um projeto de doutoramento em Ciências da Educação, especialidade de Desenvolvimento Curricular. Email: rdasilva@gmail.com.
} 


\section{Abstract \\ Curriculum, memory and fragility: contributions to (re)think education in Guinea-Bissau}

This paper explores issues of memory in the construction of the curriculum in GuineaBissau. Moving from the macro (political) level of curriculum decisions, the article seeks to unravel the role of memory in the process of curriculum construction. I argue that the peripheral and external dependency of Guinea-Bissau constitutes the major factor underlying the difficulty of constructing the curriculum in an independent and autonomous manner. In fact, in most cases, the construction of the curriculum is an external process based on traveling reforms. The analysis also highlights that memory has been used more to legitimize a particular educational decision than to strengthen and/or to consolidate educational identity(ies) in Guinea-Bissau.

Keywords: curriculum; memory, fragility, trans-nationalization of education, peripheries.

\section{Resumé \\ Curriculum, mémoire et fragilité : contributions pour (re)penser l'éducation en Guinée-Bissau}

L'article cherche, de façon exploratoire, à comprendre si et comment les problèmes de mémoire sont présents dans la construction du curriculum dans un petit état fragile et périphérique du système mondial, la Guinée-Bissau. L'analyse se concentre sur le domaine macro (politique et administrative) de décision sur le curriculum et cherche à mettre à jour certaines nuances qui affectent ce processus.

La réflexion nous permet de dire que, en raison de sa condition périphérique et de sa dépendance à l'aide externe, la Guinée-Bissau a des difficultés à diriger la construction du curriculum de manière indépendante et autonome. En fait, on a constaté que, dans la plupart des cas, la construction du curriculum est un processus externe, sur la base de "réformes voyageuses " dont on ne sait souvent ni d'où elles viennent ni à qui elles se destinent. L’analyse a également montré que la mémoire parait être utilisée plus pour légitimer une option éducative particulière que pour renforcer et / ou consolider l'/les identité/s de l'éducation en Guinée-Bissau.

Mots-clé: curriculum, mémoire, fragilité, transnationalisation de l'éducation, périphérie(s). 


\section{Introdução}

É hoje do domínio comum que a educação é um dos principais eixos estruturantes do desenvolvimento pessoal, social e profissional de cada cidadão e, por conseguinte, de cada comunidade. Assim se compreende que a educação, como projeto de formação intelectual, cultural e humana, que procura responder a necessidades específicas de cada contexto, encontre na escola o espaço privilegiado para a sua concretização. É nesta ordem de ideias que Machado e Gonçalves (1991) assinalam que a escola, concebida como instituição formal de educação, não pode deixar de ter um currículo, consubstanciado num determinado conteúdo que é objeto de transmissão, objetivo de formação ou esteio de reflexão e transformação. Quando isto acontece, isto é, quando o currículo se dimensiona numa perspetiva transformadora veicula uma ação cultural que se inscreve num processo de consciencialização crítica (Freire, 1987).

É nesta linha de pensamento que Moreira e Silva (1995: 7-8) afiançam que o currículo "não é um elemento inocente" nem veicula uma "transmissão desinteressada do conhecimento social"; pelo contrário, o currículo está "implicado em relações de poder, transmite visões sociais particulares e interessadas e produz identidades individuais e sociais particulares". Assim se justifica o interesse que este artefacto sociocultural tem granjeado ao longo dos tempos, dada a preponderância que assume na organização da educação e, consequentemente, da própria sociedade. Ora, parece-nos que não suscita controvérsia a ideia de que não podemos eximir-nos de refletir sobre a importância do currículo se quisermos apropriar-nos de contributos que nos ajudem a compreender a evolução do empreendimento educativo na Guiné-Bissau, dado tratar-se do contexto que privilegiamos nesta análise.

Contudo, existem ainda dois aspetos que, em nosso entender, se revelam determinantes nesse processo evolutivo: a influência que determinados poderes transnacionais têm tido na definição das políticas educativas e curriculares de cada país; o contexto em que essas políticas são implementadas, nomeadamente nos países do Sul global, por norma mais dependentes de apoio externo e, por isso, mais vulneráveis a certas pressões e/ou imposições externas.

É, pois, em torno dos aspetos que acabámos de referir que se estrutura este texto. No primeiro ponto tecemos algumas considerações sobre a importância do currículo na configuração do fenómeno educativo e seus reflexos em termos culturais e sociais. Num segundo ponto abordamos a transnacionalização da educação por se tornar relevante na compreensão de determinados mecanismos de poder que influenciam os Estados de certos países mais frágeis e os impedem de organizarem e orientarem os seus próprios sistemas educativos. No terceiro segmento de análise procedemos a uma breve caracterização do contexto em que incide este estudo, a Guiné-Bissau, para, em momento posterior, averiguarmos como é que as questões da memória se dimensionam no processo de construção curricular neste Estado periférico do sistema mundial 
e que fragilidades daí resultam em termos educativos. No último ponto, que intitulamos Considerações finais, identificamos algumas linhas de força que permitem olhar o futuro e delinear novas análises e, por conseguinte, novas propostas de mudança.

\section{A preponderância social, cultural e política do currículo}

Como referimos na introdução deste texto, como artefacto social, cultural e político, o currículo não é neutro nem inócuo. A intensa relação que mantém com o conhecimento confere-lhe um lugar de destaque na própria arquitetura educativa e nas relações que se estabelecem entre a escola e determinados grupos de classes sociais distintas. Sendo reconhecido como um território de lutas pela hegemonia, o currículo interfere, de forma direta ou indireta, quer na legitimação do conhecimento que, em determinado momento, é considerado como conhecimento oficial (Apple, 1999), quer na produção e/ou consolidação de determinadas identidades sociais particulares que condicionam a inclusão ou exclusão de cada indivíduo na escola e, mais tarde, na sociedade.

É nesta ordem de ideias que currículo e conhecimento se (re)configuram e, em simultâneo, se assumem como produtos e produtores de relações sociais, num processo que Silva (2002) afiança não conseguir manter-se alheio aos interesses de certos grupos específicos que tendem obter na escola um protagonismo semelhante ao poder e à influência que têm na sociedade. A educação assume-se, assim, como um terreno vantajoso para as classes dominantes veicularem as suas ideias, os seus valores e as suas visões do mundo (Jansen, 2003; Kassaye, 2013; Le Grange, 2013; Soudien, 2010), o que lhes permite, como reiteram Khan \& Morgado (2013: 80), garantir "a reprodução de uma dada cultura e a perpetuação da estrutura social vigente”. Isso só é possível porque o currículo resulta do que Apple (1999: 51) denomina por tradição seletiva, um processo que permite aos grupos mais influentes definirem o conhecimento considerado como mais legítimo, enquanto o conhecimento de outros grupos "raramente vê a luz do dia".

Como se constata, a cultura é um referente fundamental na configuração e concretização do currículo, "uma vez que o molda e, em simultâneo, é moldada por ele", o que lhe consigna um carácter claramente político que exibe e lhe permite ser reconhecida como um fator determinante na melhoria, ou debilidade, da coesão social (Khan \& Morgado, 2013: 80). Torna-se, assim, visível a grandeza formativa do currículo, bem como a sua influência na (re)produção de relações sociais e na configuração de determinadas identidades, motivo pelo qual tem sido um terreno de disputas a diversos níveis (ver, por exemplo, Jansen, 2003; Kassaye, 2013; Le Grange, 2013). Contudo, a sua legitimação tem-se processado a diferentes ritmos históricos e sociais que não podem ter uma leitura centrada unicamente em pressupostos externos. 
Importa, por isso, problematizar se os curricula desenvolvidos e implementados nos anos mais recentes, no âmbito da cooperação em educação entre países de língua oficial portuguesa, têm propiciado uma verdadeira vivência democrática, assumindo-se como meios diferenciação pedagógica e de desenvolvimento e integração pessoal e social de estudantes oriundos de contextos de socioculturais distintos, ou se, pelo contrário, se têm limitado e transmitir e a legitimar o conhecimento válido nos países cooperantes e a difundir determinadas ideologias e políticas dominantes, em detrimento de outras igualmente válidas.

No fundo, trata-se de averiguar se, no âmbito da cooperação portuguesa, o currículo se tem conseguido manter à margem da tendência de dominação epistemológica que caracteriza muitos dos países ditos 'mais desenvolvidos' quando em processo de interação com os seus parceiros, evitando, assim, a perpetuação de algumas marcas coloniais, com efeitos menos desejáveis, resultantes de um passado ainda próximo.

Estas questões tornam-se, ainda, mais prementes se tivermos em conta, como lembram Ferreira, Faria e Cardoso (2015: 8), que "o panorama global da cooperação para o desenvolvimento está em mutação acelerada", com um alargamento do número de atores envolvidos, pese embora muitas das políticas públicas que hoje se implementam na generalidade desses países sejam definidas no âmbito de um fenómeno de transnacionalização, com reflexos intensos a vários níveis, em especial na educação.

\section{Transnacionalização da educação}

Podemos considerar que cada Estado segue uma agenda globalmente estruturada (Dale, 2004) e estamos perante a existência de uma global education policy (GEP) (Robertson, 2012; Verger, Novelli, \& Altinyelken, 2012). Este fenómeno que, numa primeira instância, é observável através de efeitos económicos, torna-se mais visível pela introdução de "padrões de eficiência e qualidade, pela privatização de serviços e pela economização do conhecimento, aceitando-se que, a nível político, são cada vez mais convergentes os modos de regulação das políticas educacionais e que, a nível cultural, são transnacionalizados padrões comuns que resultam do reconhecimento de princípios quanto a modos de ser e de viver" (Pacheco, 2009: 108).

Esta promoção é realizada por organizações supranacionais e transnacionais através da imposição das suas agendas, tentando conjugar também fatores culturais e económicos, através de relatórios, pareceres e da criação de rankings entre os países, mas, essencialmente, estas políticas educativas transnacionais promovem uma abordagem centrada nos testes definida pela abordagem centrada nos resultados e em standards como, por exemplo, o Programme for International Student Assessment (PISA), o Trends in International 
Mathematics and Science Study (TIMSS), o Programme d'analyse des systèmes éducatifs de la CONFEMEN (PASEC), o Southern African Consortium for Monitoring Education Quality (SACMEQ), o Progress in International Reading Literacy Study (PIRLS) e o Latin American Laboratory for the Assessment of the Quality of Education (LLECE) (Burbules \& Torres, 2000; Geo-Jaja \& Zajda, 2005; Kamens \& Benavot, 2011; Pacheco \& Marques, 2014; Pacheco \& Pereira, 2007; Teodoro \& Estrela, 2010). Estes rankings e comparações, entre países de grande escala, requerem testes estandardizados e consequentemente perguntas estandardizadas, que pressupõem que todos os currículos são iguais e que todos os alunos aprendem o mesmo ao mesmo ritmo. Como estes pressupostos não estão reunidos, levam à definição de uma agenda global para a educação e à consequente pressão para um core currículo mais convergente a nível global, apesar de haver indícios de que existe mais do que uma forma de estruturar o currículo para atingir melhores resultados (Anderson-Levitt, 2003, 2008; Pacheco, 2011, 2014).

Neste contexto de GEP, os países do Sul global têm uma intensidade de influências globais superior, pois estes países, essencialmente os mais pobres têm uma grande dependência de ajuda externa em diferentes modalidades, como por exemplo em termos de financiamento, informação e de especialistas (Jansen, 2003; Verger et al., 2012). Nestes contextos há também uma grande capacidade - material e ideológica - para agentes externos definirem agendas e as prioridades nos países (Jansen, 2003; Verger et al., 2012).

Desta forma, os Estados através destes mecanismos de poder/autoridade, especialmente de países pequenos, frágeis e do Sul global, veem reduzida a sua capacidade de "steer their education system" (Ball, 2012: 138), uma realidade também reconhecida por outros autores (Crossley, 2001; Williams, 2009; Jansen, 2003; Soudien, 2010; Kassaye, 2013; Le Grange, 2013).

O termo "Estado frágil” é um conceito contestado, especialmente pelos países que são etiquetados como tal, levando algumas agências a utilizar o termo Estado "resiliente" sem, contudo, alterar os pressupostos inerentes ao conceito que incluem, entre outras, as seguintes características: governo fraco, acompanhado de políticas ineficientes e instituições ainda não consolidadas, quer por falta de vontade de seus governantes, quer por incapacidade política ou económica (Brannelly, Ndaruhutse, e Rigaud 2009, Davies 2011, Kirk de 2007, Bengtsson 2011). Embora não exista uma definição consensual do que constitui um Estado frágil e o que pode ser designado como frágil, parece haver um certo consenso de que este não se limita às áreas afetadas por conflito (Davies 2011, OECD 2006). De acordo com Davies (2011) podemos identificar sete características como sendo as mais comuns e que devemos ter em consideração quando falamos em fragilidade: 
- deficits of governance;

- inability to maintain security;

- inability to ensure essential needs;

- spatial polarization of identities;

- ungovernable flows of aid;

- opaque decision-making by a small elite;

- erosion of the people's trust in the state.

Estas características parecem ser mais úteis na análise dos países do que a aplicação do termos "Estado frágil" devido a focar a atenção em dimensões específicas de fragilidade em contextos complexos, caracterizados pela mudança rápida e constante. Por esta razão usamos o termo fragilidade ao longo do artigo, já que "Estado frágil" pode ter uma conotação negativa, para além de tratar os países como uma entidade homogénea.

A política educativa tal como a conhecíamos foi alterada, mas também a forma como pensamos e estudamos estas políticas, pois as organizações internacionais não são órgãos externos ao Estado, são mais externas a uns Estados do que a outros, para além de serem agentes políticos relevantes na governação da educação (Robertson, 2012; Verger et al., 2012).

Neste contexto de transnacionalização da educação

"Not only the sources of authority have been dispersed away from the national, but the state itself - and with it education as public space - has been transformed. This has not been the result of global steamroller, but rather of complex reworking, re/bordering and re/ordering of education spaces to include a range of scales of action" (Robertson, 2012: 49).

Importa também salientar para esta análise os diferentes contextos/níveis de decisão curricular - político-administrativo, de gestão e de realização (Pacheco, 2007), pois como sustenta Anderson-Levitt (2008), embora haja esta tendência para a aparente uniformização curricular a nível mundial, esta está apenas a verificar-se no contexto/nível de decisão curricular político-administrativo (macro), pois o que se passa nas salas de aula (contexto de realização) varia.

Deste modo, podemos afirmar que organizações com várias tipologias e mandatos atualmente veiculam em muitas partes do mundo reformas educativas e um conjunto de políticas educativas similares em locais muito diversos em termos culturais e de desenvolvimento económico. Assim, a mudança educacional sistemática tornou-se um fenómeno global (Carson, 2009) aparecendo reformas viajantes que se instalam nos sistemas educativos e provocam "shifts from hierarchy to network as the preferred model" não se sabendo de onde vêm e para onde vão (Steiner-Khamsi, 2012: 8). 


\section{Guiné-Bissau - breve caracterização}

A Guiné-Bissau é um pequeno Estado da África Ocidental com uma superfície de $36,125 \mathrm{~km}^{2}$, aproximadamente com 1,6 milhões de habitantes e com uma taxa média de aumento da população estimada em 3\% ano (MENCCJD, 2011; MEPIR, 2011). No Índice Ibrahim ${ }^{1}$ encontra-se na posição 45 (de 54) com uma classificação de 35,7 (em 100), sendo o país com pior classificação da África Ocidental. Ainda neste índice apresenta, desde 2011, uma deterioração dos indicadores referentes às categorias Participation \& Human Rights, Sustainable Economic Opportunity e Human Development, este último que inclui a educação. Porém, na subcategoria Segurança Nacional apresenta valores acima da média continental (Mo Ibrahim Foundation, 2015). Desde a ocupação colonial portuguesa até à atualidade pode ser considerado um país com uma frágil coesão nacional, com um legado de conflitos, "fragmentado e batido por vagas exteriores" (Pelissier, 1989b: 276). A independência do jugo colonial português foi declarada de forma unilateral a 24 de Setembro de 1973, após onze anos de luta armada para a libertação nacional, sendo reconhecida por Portugal em 1974 e, desde essa altura, até 1991 sob a égide de um partido único (Pelissier, 1989b; Sousa, 2012a, 2012b). A liberalização das políticas económicas (em meados da década de 1980) e a adoção do multipartidarismo como sistema político foram acompanhados pela realização das primeiras eleições multipartidárias (1994) mas também por uma elevada dívida externa fruto da implementação de um Programa de Ajustamento Estrutural que veio a ter elevados custos sociais e económicos e, de uma forma geral, provocar um descontentamento crescente entre os veteranos de guerra e o exército (Cruz, 2007; Temudo, 2008). De 1973 até ao presente ocorreu uma guerra civil, no período de 7 de julho de 1998 a maio de 1999 e 10 golpes de estado, o último em 2012, que interrompeu a segunda volta das eleições presidenciais e cuja ordem constitucional regressou em julho de 2014 (Sousa, 2012b; Temudo, 2008). A guerra civil de 1998-99 não foi um conflito de irracionalidade apolítica despoletada pela ganância, religião ou tribalismo, mas uma brotherly war, apesar das forças beligerantes incluírem algumas dimensões étnicas (Temudo, 2008). Mais recentemente, em agosto de 2015, a destituição por parte do presidente da República do governo em funções criou mais um ciclo de instabilidade política. É também considerado o primeiro narco-Estado africano e um dos Estados mais frágeis do continente (O’Regan \& Thompson, 2013; Temudo, 2008). Este contexto de crise e fragilidade permanente levou a que as Nações Unidas em 2009 reformulassem o seu mandato no país - de uma abordagem de desenvolvimento para uma de segurança - constituindo esta mudança um marco importante, pois passa a ser reconhecido que as reformas devem ser

1 O Ibrahim Index of African Governance é um índice que fornece uma avaliação estatística anual do desempenho da governação em cada país Africano e inclui os seguintes indicadores Safety \& Rule of Law; Participation \& Human Rights; Sustainable Economic Opportunity; Human Development. 
realizadas através de um programa com foco nos setores da defesa, segurança e justiça (Barros \& Rivera, 2011).

O produto interno bruto per capita é um dos mais baixos do mundo (1270 dólares americanos), as infraestruturas são pobres, os indicadores sociais baixos e a taxa de pobreza é de aproximadamente 64,7\% (MEPIR, 2011; UNESCO Institute of Statistics, 2011). Atualmente o país vive um ambiente de crise alimentar e um state failure e ao longo do tempo tem experienciado um longo processo de depeasantization do meio rural, ampliado pelo aumento de matrículas de jovens na escola (Temudo \& Abrantes, 2013; 2015). Devido à sua condição económica e social, encontra-se bastante dependente da ajuda pública ao desenvolvimento, bilateral e multilateral, particularmente para os serviços públicos, sendo a educação e a saúde os setores com maior dependência. Neste contexto de fragilidade a sociedade civil (essencialmente as ONG e a Igreja Católica) desempenha um papel crucial na assistência às populações mais desfavorecidas e na consolidação do Estado, com relevo para as áreas da educação, da saúde, direitos humanos, ambiente e no processo de consolidação da paz (Barros, 2012). Apesar de a língua portuguesa ser oficial, apenas aproximadamente $5 \%$ da população a têm como língua materna e cerca de $10 \%$ é capaz de a falar. A maioria dos habitantes fala uma ou mais das 20 línguas existentes no país, incluindo o crioulo (Benson, 2010; Monteiro, 2005; Observatório da Língua Portuguesa, 2009). Das cerca de 20 línguas nacionais as mais faladas/representativas são o Balanta, o Fula, o Mandinga, o Manjaco e o crioulo, que é considerada a língua franca, falada por $30 \%$ a $40 \%$ dos habitantes (Benson, 2010; Monteiro, 2005).

As condições de fragilidade do Estado, como má governação, corrupção, baixos níveis de coesão social, desigualdades e exclusão podem afetar a educação (Brannelly, Ndaruhutse, \& Rigaud, 2009; INEE, 2010). Na Guiné-Bissau, estes aspetos refletem-se, por exemplo: numa taxa líquida de escolarização primária de $67 \% ; 13 \%$ das salas de aula de quirintim ${ }^{2}$; ausência de livros escolares; número de dias de aulas limitado, devido às greves por causa dos atrasos no pagamento de salários aos professores; elevadas percentagens de insucesso e de abandono escolar; muitos professores em exercício com baixos níveis de formação inicial; a necessidade de contratar em média cerca de 450 professores por ano para alcançar a escolarização universal para o $1 .^{\circ}$ e $2 .^{\circ}$ ciclos do ensino básico em 2020; e a mudanças constantes do titular da pasta da educação, tendo tomado posse desde a independência e até à atualidade 35 ministros da educação (Lopes, 2014; MENCCJD, 2011; UNESCO, 2013 \& dados dos autores). Assim, o sistema educativo guineense, apesar das mudanças que foram ocorrendo, continua a ser " descontinuado por reformas inacabadas e por atuações avulsas, por vezes sem prumo, um sistema que ficou desajustado, instável, 
ineficiente e altamente seletivo" (Monteiro, 2005: 131). Um dos fatores apontados para esta situação é a herança da educação colonial, que chegou mesmo a ser designada como "A origem do mal" (Koudawo, 1996: 69).

Dos países que tiveram influência colonial de Portugal, a Guiné-Bissau foi o último a possuir um liceu público (em 1949), quando em Cabo Verde, por exemplo, já existia um desde 1917 com a maioria do seu pessoal docente de origem Cabo-verdiana (Chabal, 2002). Um ano após o início da guerra libertação/ colonial (1964) "only a very small proportion of Guinean children had access to primary education. Virtually no African had received secondary education" (Chabal, 2002: 22) e 99\% da população era iletrada, sendo a educação dos africanos (indígenas ${ }^{3}$ ) desde 1940 da responsabilidade da Igreja Católica, após a assinatura de uma concordata com o Vaticano. A Igreja Católica detinha uma quantidade muito reduzida de oferta educativa tendo em conta a população do país e escolas sem um ciclo de ensino primário completo, sendo apenas permitido o acesso à escola pública aos assimilados". Após o início do plano "Por uma Guiné melhor" ${ }^{5} \mathrm{o}$ acesso à educação pública teve melhorias em termos de acesso, tendo por exemplo o poder colonial transformado guarnições militares em estabelecimentos de ensino. Contudo, apesar destes esforços, o acesso continuou a ser reduzido (Cá, 2008; Mendy, 2008; Monteiro, 2005; Chabal, 2002; Silva, 1997).

O Partido Africano da Independência da Guiné e Cabo Verde (PAIGC) na sequência do Congresso de Cassacá em fevereiro de 1964 iniciou o seu programa de educação nas zonas libertadas ${ }^{6}$ promovendo a gratuitidade e obrigatoriedade da educação, contudo, devido à guerra que decorria as crianças só iniciavam a escolarização com 10 anos de idade (Cá, 2008; Monteiro, 2005 Chabal, 2002). Amílcar Cabral, líder do PAIGC na altura e "outstanding leader of African decolonization but also as a political thinker and strategist of unusual merits" (Rudebeck, 2006: 89), teve uma influência grande na definição das políticas educativas e uma preocupação particular com a escolarização das meninas, implementado estratégias para favorecer a sua escolarização e prevenir o abandono precoce (Cá, 2008; Chabal, 2002).

No pós-25 de Abril de 1974 com a saída de Portugal da Guiné-Bissau o sistema educativo herdado pelo colonialismo português foi sendo alterado com base nas experiências das zonas libertadas e por condicionalismos e exigências impostas do exterior, provenientes de organizações com várias tipologias e mandatos, tornando-se estas mais evidentes a partir da liberalização

3 Designação utilizada na altura pelo poder colonial.

4 Designação utilizada para caracterizar os africanos que cumpriam 4 requisitos que indicavam que essas pessoas eram portugueses (1. dedicação pelos interesses da Nação Portuguesa; 2. falar a língua portuguesa; 3. possuir os meios necessários à sua subsistência; 4. ter bom comportamento atestado). 5 Designação pela qual ficou conhecida a política de promoção de justiça social, desenvolvimento económico, reforço das instituições tradicionais da Guiné-Bissau durante a governação 1968 e 1973 do General António de Spínola.

6 Zona do país sobe o domínio do PAIGC. 
económica e política (em meados da década de 1980) (Carr-Hill \& Rosengart, 1982, 1983; Pehrsson, 1996; Monteiro, 2005). Contudo, a estrutura do sistema educativo permaneceu inalterada até ao início de 1990, apesar das várias tentativas de elaborar e aprovar uma Lei de Bases do Sistema Educativo, que se veio, apenas, a verificar no ano letivo 2009/2010 (Daun, 1997; Carr-Hill \& Rosengart, 1982, 1983; Pehrsson, 1996; Monteiro, 2005). A disponibilidade de financiamento externo é a principal condição para ocorrerem intervenções no sistema educativo, parecendo haver uma insipiente coordenação entre os vários intervenientes e projetos/ programas, mesmo do mesmo financiador (Carr-Hill \& Rosengart, 1982, 1983; Pehrsson, 1996; Monteiro, 2005; Furtado, 2005). Desta forma, as intervenções no sistema educativo apresentam-se fragmentadas, com uma duração confinada à duração dos projetos/ programas, com as diferentes organizações a deixarem pouca margem de negociação ao Ministério da Educação, pelo menos a nível macro (político-administrativo) (Carr-Hill \& Rosengart, 1982, 1983; Pehrsson, 1996; Monteiro, 2005; Furtado, 2005; A. Barreto, 2012; Silva, Santos \& Pacheco, 2015). Apesar das melhorias alcançadas desde a independência, num quadro de grande fragilidade e de ter havido um grande progresso no acesso, o sistema educativo ainda não chega a todos os guineenses, não cumprindo desta forma os desígnios da Constituição guineense e da Lei de Bases do Sistema Educativo.

O sistema educativo também parece ser marcado por uma grande indefinição política, descontinuidades, contradições, reformas inacabadas, ineficiência, desajustado da realidade do país, instável e com grandes diferenças entre meio urbano e rural (Carr-Hill \& Rosengart, 1982, 1983; Pehrsson, 1996; dauns, 1997; Monteiro, 2005; Furtado, 2005).

As taxas de escolarização são baixas, a título exemplificativo a UNESCO (2013) refere que a Guiné-Bissau apresenta a taxa mais baixa, do conjunto de países da África Ocidental, de alunos que completam os primeiros quarto anos de escolaridade.

O sistema educativo continua a ser centralizado, burocratizado e totalmente politizado, ficando patentes nas palavras de Furtado (2005: 671) que prevalece uma visão da educação centrada no Estado, "no Ministério da Educação e na pessoa do Ministro que ainda detêm um controlo político sobre o sector". Porém, a atual Lei de Bases do Sistema Educativo deixa em aberto que o currículo não é normativo, podendo as escolas utilizar outro currículo para além do nacional, desde que aprovado pelo Ministério da Educação. Uma outra característica é que a grande parte do orçamento destinado à educação historicamente é canalizado para o pagamento dos salários dos professores (atualmente representa 94\%), sendo muito importante para o financiamento da educação o contribuindo das famílias (UNESCO, 2013).

O sistema educativo ao longo do tempo tem vindo a manter uma tendência elitista e urbana, pois os meios estão concentrados sobre os poucos alunos que 
permanecem no sistema, privilegiando-se o número de matrículas em detrimento da qualidade (Carr-Hill \& Rosengart, 1982, 1983; Pehrsson, 1996; Monteiro, 2005; Furtado, 2005).

As características do sistema educativo implementado em 1974 parecem estar ainda bastante presentes na atualidade, persistindo políticas e práticas, apesar de os discursos políticos estarem impregnados de atualidade (Pehrsson, 1996; Monteiro, 2005; Furtado, 2005; A. Barreto, 2012; Silva, Santos \& Pacheco, 2015).

$\mathrm{O}$ incentivo à iniciativa privada e a uma regulação mercantil do sistema educativo está presente, bem como uma tendência para a retylerizaçãa $O^{7}$ das práticas curriculares. Porém, parece emergir um certo paradoxo, pois se por um lado se incentiva a iniciativa privada, por outro reconhece-se que parte da população, embora pague pela educação a que tem acesso, não tem capacidade financeira para tal (Silva, Santos \& Pacheco, 2015). Este aspeto pode também estar relacionado com fatores históricos, políticos e socioculturais, pois em algumas zonas do país as populações estão mais propensas à participação na educação, sendo o número de escolas de iniciativa comunitária, nas suas várias tipologias e configurações, mais comuns em algumas regiões (A. G. Barreto, 2012; Lopes, 2007; Ribeiro, 2001; Sanhá, 2014).

Relativamente ao currículo, com a exceção de projetos experimentais que não seguiam o currículo nacional (Benson, 1994; Gomes, 1994; Gomes \& Pereira, 2004; Hovens, 1994, 2002; Santos, 1994), pode ser caracterizado como sendo concebido para uma população homogénea, urbana, falante de língua portuguesa e que vai prosseguir estudos. Todas estas características tornam o currículo adequado a uma pequena franja da população guineense, parecendo que a língua contínua a ser um instrumento de dominação como era no período colonial.

Apesar de todas estas fragilidades, um estudo recente (UNESCO 2013) verificou que a educação na Guiné-Bissau tem um forte impacto no domínio social, particularmente o ensino básico, tendo em conta vários indicadores mensuráveis, tais como a reprodução, a saúde, a proteção da mulher e o civismo. Porém, a oferta de uma via profissionalizante, com potencial em termos de efeitos económicos e sociais, contínua a ser reduzida.

Os pais e a sociedade civil têm uma participação ativa na educação formal, na criação de escolas, no pagamento de propinas, na disponibilização de incentivos financeiros e não financeiros que permitem que num quadro de grande fragilidade e instabilidade certas escolas nunca deixem de funcionar. Estas escolas criadas pelas comunidades parecem desfrutar de maior notoriedade e o seu pessoal docente é mais respeitado por parte da comunidade do

7 Entende-se por esta palavra o regresso a Tyler, aceitando-se que o currículo é um plano, definido pela administração (normativo), embora possa ser gerido pelos professores, desde que essa gestão seja controlada pelo currículo nacional e pela avaliação estandardizada. 
que os que trabalham nas escolas públicas. Porém, estas têm uma tendência para seguir o modelo das escolas públicas (A. G. Barreto, 2012; Lopes, 2007; Ribeiro, 2001; Sanhá, 2014). Assim, surgem paralelamente às escolas estatais uma série de iniciativas comunitárias ${ }^{8}$, religiosas e privadas de serviços educativos, entre elas escolas corânicas com 3 tipologias diferentes ${ }^{9}$ (estima-se que $33 \%$ da população é muçulmana), devido ao vazio do estado em responder às necessidades, principalmente no meio rural, ainda mais prementes se tivermos em conta a grande percentagem de jovens que caracterizam a população da Guiné-Bissau (Mendy, 2008; Lopes, 2007; Monteiro, 2005; Baldé, 2010; UNESCO, 2013). Segundo os últimos dados disponíveis, 15\% e 14\% dos alunos do Ensino Básico e Secundário, respetivamente, frequentam escolas comunitárias e madraças (UNESCO, 2013). Também por vezes a grande diversidade cultural é um entrave ao acesso à escola, por exemplo, na zona leste do país muitas meninas não frequentem a escola devido a práticas culturais ancestrais e a crenças religiosas (Baldé, 2010; UNESCO, 2013; Mendy, 2008; Lopes, 2007; Monteiro, 2005).

O setor da educação na Guiné-Bissau nos últimos 40 anos foi dos que mais teve apoio externo, quer de agências multilaterais (e.g., Banco Africano de Desenvolvimento, Fundo das Nações Unidas para Infância, Programa das Nações Unidas para o Desenvolvimento, Banco Mundial) quer bilaterais (e.g., Suécia, Holanda e Portugal). É de destacar a importância da Suécia (1969 a 1999) que em 1999 se retirou da Guiné-Bissau e "com ela foi-se praticamente a ajuda externa à educação, pelo menos aquela que era gratuita, flexível e fácil de mobilizar" (Monteiro, 2005: 135). Foi uma cooperação bilateral do tipo de assistência ao setor dirigida a pontos considerados cruciais e com ênfase nas seguintes áreas: coordenação, formação de professores, pesquisas pedagógicas, construção e reparação de escolas, e desenvolvimento de meios de ensino. Realizou apoio direto ao orçamento da educação e teve uma participação fundamental na reforma educativa que ocorreu no início dos anos 90. Para Pehrsson (citada por Monteiro, 2005: 129) "sem a ajuda externa, não havia educação na Guiné-Bissau”, o que reforça a vulnerabilidade em relação a decisões e apoios financeiros externos.

Um outro fator que influenciou grandemente o sistema educativo foram os Planos de Ajustamento Estrutural, consequência do empréstimo contraído pelo estado Guineense ao Fundo Monetário Internacional e ao Banco Mundial. Os condicionalismos associados ajudaram a fragilizar ainda mais o sistema educativo, contribuindo muitas das medidas adotadas para tornar

8 Escolas onde os pais dos alunos se organizam e constituem a própria escola. O Governo da GuinéBissau regulamentou a sua criação, no entanto, continua a ser da responsabilidade das comunidades a sua criação e organização estando previsto o apoio do estado no pagamento de parte do salário do professor.

9 Madjlis, Madraças e Escolas Mistas. 
os custos associados à educação proibitivos para a maioria da população (privatização do sistema educativo) eliminando a igualdade de oportunidades, aumentar o rácio professor-aluno, desmotivação dos professores e migração dos professores mais qualificados devido ao baixo salário e à deterioração do sistema educativo fruto da sua liberalização (Cá, 2008; Cruz, 2007; Monteiro, 2005).

O Banco Mundial iniciou a sua influência no sistema educativo a partir de 1985. O projeto que parece ter sido mais significativo foi o Firkidja, implementado de 1997 a 2005, com uma interrupção no período da guerra civil (1998 a 1999). Este projeto foi considerado fundamental no período do 1997 a 2005 para o funcionamento do sistema educativo, principalmente a parte de administração. (Banco Mundial, 2005; Djaló, 2009; Monteiro, 2005). Este projeto parece ter também influenciado uma maior participação das organizações da sociedade civil no sistema educativo, o aumento da taxa bruta de escolarização através de medidas como a construção e a reabilitação de escolas, a eliminação das propinas para o ensino básico, o fornecimento de materiais escolares e o pagamento dos salários em atraso aos professores (Banco Mundial, 2005; Djaló, 2009; Monteiro, 2005).

O sistema educativo guineense é marcado por "descontinuidades e contradições, decorrentes de reformas inacabadas" (Monteiro, 2005: 131) e "vem sendo amplamente modificada pelos organismos internacionais, na busca da reconstrução do sistema de ensino e na tentativa de diminuir os elevados índices de evasão e de reprovação e trazer melhoria da qualidade de ensino" (Cá, 2008: 227).

No entanto, apesar destes aspetos, os sistemas educativos como o da Guiné-Bissau apresentam uma enorme resiliência. Esta constitui uma das características dos sistemas educativos em contexto de emergência/fragilidade/ crises prolongadas/reconstrução pós-conflito, uma vez que estes se reconstroem, mesmo nas circunstâncias mais desafiantes, com o apoio das comunidades, devido ao papel simbólico e estratégico atribuído à educação (Brannelly et al., 2009; INEE, 2010; Kirk, 2007; Nicolai, 2009). O que marca esta resiliência, no caso da Guiné-Bissau, é: i) o conflito de 1998/1999 acabou por não afetar a dinâmica de crescimento das taxas brutas de escolarização nos anos que se seguiram; ii) antes (nas áreas libertadas) e depois da independência as comunidades organizaram várias estratégias para começar e/ou continuar o acesso à educação; iii) no ano letivo 2009-2010 e 2010-2011, que foram dos mais estáveis dos últimos anos, legislação fundamental foi aprovada (e.g., Lei de Bases do Sistema Educativo, Estatuto da Carreira Docente), foram realizados os exames nacionais e os anos letivos funcionaram sem grandes interrupções (MENCCJD, 2011; Monteiro, 2005). 


\section{Memória, currículo e fragilidades}

Como referimos na introdução deste texto, a nossa análise pretende averiguar, ainda que de forma exploratória, como é que as questões da memória estão presentes na construção do currículo num pequeno Estado frágil e periférico do sistema mundial, a Guiné-Bissau. Uma análise que se centra no domínio macro, no contexto/ nível político-administrativo de decisão curricular, chamando a atenção para a importância de investigar as questões do currículo em sociedades que emergiram de conflitos e, sobretudo, quando nelas estão envolvidas organizações de desenvolvimento na reconstrução dos sistemas educativos (Weldon, 2009).

Países como a Guiné-Bissau sofrem uma grande influência externa de várias organizações, limitando a sua capacidade de conduzir o seu próprio sistema educativo. No caso particular da Guiné-Bissau, as organizações internacionais, como, por exemplo, o Banco Mundial, a UNICEF, a Cooperação Bilateral (Sueca, Portuguesa, UEMOA, Cubana, entre outras) têm conseguido que as suas agendas sejam tidas em conta na definição de políticas educativas a nível macro, relegando, muitas vezes, os responsáveis pela educação a nível nacional para um papel secundarizado (ver, por exemplo, Pehrsson 1996; Monteiro, 2005; Furtado, 2005; Cá, 2008; Silva, Santos \& Pacheco, 2015). De uma forma global, desde a reforma dos anos 90 os primeiros 6 anos de escolaridade parecem ser os que sofrem maior influência das organizações multilaterais e organizações não governamentais e da Cooperação Sueca e o ensino dos restantes anos de escolaridade de organizações bilaterais (Cooperação Portuguesa, UEMOA, Cubana). Neste caso, isso deve-se aos modelos de cooperação bilaterais que escolheram a escola como unidade de intervenção, como é o caso da cooperação portuguesa. Porém, não podemos simplificar este processo ao ponto de assumirmos que as agências internacionais são os únicos atores deste processo. Por exemplo, a educação básica do $1 .^{\circ}$ ao $4 .^{\circ}$ ano é uma meta promovida por estas organizações e um objetivo para o país desde a luta de libertação do jugo colonial de Portugal (1964-1974).

Quando nos debruçamos sobre as questões de memória na construção do currículo, os dados que temos disponíveis parecem indicar que nos primeiros anos após a independência estas questões estiveram mais presentes do que na atualidade. Este aspeto parece estar associado à proximidade temporal da "vitória" da luta de libertação nacional e à figura e pensamento de Amílcar Cabral, que se pode traduzir na frase "Cabral ka morri" ${ }^{10}$. Um outro fator que surge associado ao período pós-independência e que cruza memória e fatores ideológicos vividos nesse período foi a adoção de determinadas políticas educativas como é o caso da introdução do trabalho produtivo. $\mathrm{O}$ trabalho produtivo foi instituído como política educativa na pós-independência e pretendeu gene- 
ralizar uma prática das áreas libertadas que consistia na ligação do trabalho manual com o intelectual, neste caso o trabalho rural com a participação dos alunos na produção agrícola.

Nestes primeiros anos após a independência, consideramos importante destacar o papel que Paulo Freire e a sua equipa do Instituto de Ação Cultural (IDAC) realizaram na Guiné-Bissau e que se encontra documentado (Freire, 1984, 2008). Esta experiência de (re)construção curricular é interessante, pois contraria a perspetiva hegemónica destes processos de colaboração. O trabalho desenvolvido partia do pressuposto que "os que ajudam e os que são ajudados se ajudam simultaneamente" não transformando o ato de ajudar "em dominação do que ajuda sobre quem é ajudado" (Freire, 1984: 11). Pois, as experiências não partem de uma solução "empacotada", "na verdade, as experiências não se transplantam, se reinventam" (Freire, 1984: 12). Esta perspetiva imprimiu outra dinâmica ao processo, sem contudo estar livre de tensões, embora parecendo prevalecer a perspetiva guineense.

A principal tensão que parece ter ocorrido é a questão do uso da língua portuguesa como única língua de ensino e escolarização. Este é, ainda hoje, um assunto controverso e causador de tensões, não podendo ser ignorado quando discutimos as questões da memória e do currículo.

Como se encontra documentado, no trabalho de Paulo Freire e da sua equipa (e.g., Freire, 1984, 2008), a memória de Amílcar Cabral (“O Português é uma das melhores coisas que os portugueses nos deixaram”) e das escolhas políticas durante a luta de libertação foram utilizadas para legitimar esta opção e contrariar as recomendações para o uso das línguas nacionais, incluindo o Crioulo. Esta evocação da memória vem sendo utilizada recorrentemente, durante os últimos 40 anos, para legitimar a opção tomada, sem a situar num tempo histórico. Ao referir a obra de Cabral e a sua relevância para as políticas linguísticas, Varela (2013) não deixa de considerar como "boas conselheiras" as palavras de Cabral sobre a importância do Crioulo, logo que haja condições para que possa ser usada na escolarização.

Assim, parece que após as reformas introduzidas a partir de meados da década de 1980 com os planos de ajustamento estrutural as questões de memória na construção do currículo têm sido marginais e utilizadas de forma instrumental para legitimar uma posição. $\mathrm{Na}$ maior parte dos casos, parece também que na construção do currículo na sua aceção mais ampla tem predominado uma visão externa que subalterniza os ritmos, os tempos, assim como a memória. Isto ocorre devido a estes processos serem liderados por organizações externas e pelos seus consultores/especialistas expatriados. Estes, mesmo que muitas vezes tentem, nem sempre conseguem ter em consideração o contexto e a memória, bem como "despir-se" dos seus conceitos e conhecimentos ocidentais. 


\section{Considerações finais}

O currículo como artefacto social, cultural e político não é neutro nem inócuo (Moreira \& Silva, 1995) assumindo-se assim a educação como um terreno vantajoso para as classes dominantes veicularem as suas ideias, os seus valores e as suas visões do mundo (Jansen, 2003; Soudien, 2010; Kassaye, 2013; Le Grange, 2013) resultando uma tradição seletiva (Khan \& Morgado, 2013). Porém, num contexto de GEP cada Estado segue uma agenda globalmente estruturada (Dale, 2004) tendo por base reformas viajantes que, muitas vezes, não se sabe de onde vêm e para onde se destinam. Assim, os Estados, especialmente de países pequenos, frágeis e do Sul global, veem reduzida a sua capacidade de "steer their education system" (Ball, 2012: 138) verificar-se que, na maioria dos casos, a construção do currículo é um processo externo.

Posto isto, em jeito de balanço final, importa realçar três aspetos que emergem da análise efetuada e que é necessário ter em atenção em futuras pesquisas sobre esta temática.

Em primeiro lugar, a necessidade de refletir sobre a construção do currículo em sociedades em situação de instabilidade e de fragilidade, por isso sujeitas a uma forte dependência das organizações transnacionais, frequentemente envolvidas na reconstrução dos seus sistemas educativos. Esta situação, que parece arrastar-se em pequenos países como a Guiné-Bissau, tende a desenvolver relações de poder desiguais, contribuindo para subalternizar os ritmos, os tempos, bem como a memória.

Em segundo lugar, a necessidade de uma reflexão sobre a utilização da memória na construção do currículo, não apenas para legitimar determinadas opções ou para ser usada de forma acrítica, mas por ser um constructo importante a ter em consideração e que vai para além do currículo formal para considerar os significados históricos da identidade no contexto da nação guineense.

Em terceiro lugar, compreender que a construção do currículo em países frágeis e pós-conflito tem sido uma faceta pouco investigada no campo do desenvolvimento curricular e das políticas educativas e curriculares. Parecenos, por isso, particularmente relevante continuar a aprofundar esta temática, sobretudo tendo em consideração os contextos de fragilidade e pós-conflito no âmbito dos países lusófonos.

\section{Referências}

ANDERSON-LEVITT, K. M. (2003), “A world culture of schooling?”, in K. M. Anderson-Levitt (ed.), Local Meanings, Global schooling - Anthropology and World Culture Theory. New York: Palgrave Macmillan, 1-26.

ANDERSON-LEVITT, K. M. (2008), "Globalization and Curriculum”, in F. M. Connelly, M. F. He and J. Philion (ed.), The SAGE Handbook of Curriculum and Instruction. London: SAGE Publications, 349-368.

APPLE, M. (1999), Políticas Culturais e Educação. Porto: Porto Editora. 
BALDÉ, S. (2010), Da exclusão a auto-exclusão da população muçulmana no sistema educativo guineense. Paper presented at the $7 .^{\circ}$ Congresso Ibérico de Estudos Africanos - 50 anos das independências africanas: desafios para a modernidade. Lisboa.

BALL, S. J. (2012), Global education inc: new policy networks and the neo-liberal imaginary. London: Routledge.

BANCO MUNDIAL (2005), Guinea-Bissau Basic Education Support Project. Washington, DC: Banco Mundial.

BARRETO, A. (2012), Reformas recentes no sistema educativo da Guiné-Bissau: compromisso entre a identidade e a dependência. Paper presented at the Colóquio Internacional Cabo Verde e Guiné-Bissau: percursos do saber e da ciência. Lisboa.

BARRETO, A. G. (2012). Escolas comunitárias na Guiné-Bissau: sentidos, relações e mudanças, dissertação de mestrado, ISCTE-Instituto Universitário de Lisboa, Lisboa.

BARROS, M. d. (2012), "A Sociedade Civil face ao processo de democratização e desenvolvimento na Guiné-Bissau (1991-2011)”. Africana Studia, 18: 71-82.

BARROS, M. d.; RIVERA, O. (2011). A (Re)Construção Do Estado No Contexto dos Estados Frágeis: O caso da Guiné-Bissau. Paper presented at the II Congresso "África-Ocidente" Corresponsabilidad en el Desarrollo. Huelva.

BENGTSSON, S. E. L. (2011), "Fragile states, fragile concepts: A critical reflection on the terminology of fragility in the field of education in emergencies", in Julia Paulson (ed.), Education, conflict and development. Oxford: Symposium Books, 33-58.

BENSON, C. (1994), Teaching beginning literacy in the 'mother tongue': A study of the experimental Kiriol/Portuguese primary project in Guinea-Bissau, PhD. Los Angeles: University of California.

BENSON, C. (2010), "How multilingual African contexts are pushing educational research and practice in new directions". Language and Education, 24 (4): 323-336. doi:10.1080/09500 781003678704

BRANNELLY, L.; NDARUHUTSE, S.; RIGAUD, C. (2009). Donors' Engagement: supporting education in fragile and conflict-affected states. Paris: UNESCO-IIEP,CfBT Education Trust.

BURBULES, N. C.; TORRES, C. A. (2000), "Globalization and education: an introduction", in N. C. Burbules and C. A. Torres (ed.), Globalization and education: critical perspectives. London: Routlege, 1-26.

CÁ, L. O. (2008), A constituição da política do currículo na Guiné-Bissau e o mundo globalizado. Cuiabá: Editora da Universidade Federal de Mato Grosso/CAPES.

CARR-HILL, R.; ROSENGART, G. (1982), Education in Guinea-Bissau 1978-81. The lmpact of swedish Assistance. Bissau: ASDI

CARR-HILL, R.; ROSENGART, G. (1983), "Education since independence in Guinea-Bissau”. International Journal of Educational Development, 3 (3): 325-336. doi:http://dx.doi. org/10.1016/0738-0593(83)90051-2

CARSON, T. R. (2009), "Re-thinking Curriculum Change from the Place of the Teacher", in E. Ropo and T. Autio (ed.), International conversations on curriculum studies: subject, society and curriculum. Rotterdam: Sense Publishers, 213-224.

CHABAL, P. (2002), Amilcar Cabral Revolutionary leadership and people's war (2. ${ }^{\mathrm{a}}$ ed.). London: Hurst \& Company.

CROSSLEY, M. (2001), "Cross-cultural issues, small states and research: capacity building in Belize”. International Journal of Educational Development, 21 (3), 217-229. doi:http:// dx.doi. org/10.1016/S0738-0593(00)00030-4

CRUZ, J. (2007), O Programa de Ajustamento Estrutural na República da Guiné-Bissau: Uma avaliação política e ética, dissertação de mestrado, Instituto Superior de Ciências do Trabalho e da Empresa, Lisboa. 
DALE, R. (2004), "Globalização e educação: demonstrando a existência de uma "Cultura Educacional Mundial Comum” ou localizando uma "Agenda Globalmente Estruturada para a Educação"?". Educação \& Sociedade, 25: 423-460.

DAUN, H. (1997), “Teachers needs, culturally-significant teacher education and educational achievement in an African context - the case of Guinea-Bissau”. International Journal of Educational Development, 17 (1): 59-71. doi:http://dx.doi.org/10.1016/S0738-0593(96)00028-4

DAVIES, L. (2011), “Learning for state-building: capacity development, education and fragility”. Comparative Education 47 (2): 157-180. doi: 10.1080/03050068.2011.554085.

DJALÓ, M. (2009). A Interferência do Banco Mundial na Guiné-Bissau: a dimensão da educação básica-1980-2005, dissertação de mestrado, Universidade Federal de Santa Catarina, Florianópolis.

FERREIRA, P. M.; FARIA, F.; CARDOSO, F. J. (2015), O Papel de Portugal na Arquitetura Global do Desenvolvimento: Opções para o Futuro da Cooperação Portuguesa. Lisboa: MNE e IMVF.

FREIRE, P. (1984), Cartas à Guiné-Bissau: registos de uma experiência em processo (4. a ed.). Rio de Janeiro: Terra e Paz.

FREIRE, P. (1987), Pedagogia do Oprimido (17 ${ }^{\text {a }}$ Ed.). Rio de Janeiro: Paz e Terra.

FREIRE, P. (2008), Amílcar Cabral o pedagogo da revolução. Retrieved from http://forumeja. org. br/files/amilcar.pdf

GEO-JAJA, M.; ZAJDA, J. (2005), "Rethinking Globalization and the Future of Education in Africa”, in J. Zajda (ed.), International Handbook on Globalisation, Education and Policy Research. Springer, 109-129.

GOMES, A. (1994), Avaliação “projecto português” Ensino da lingua portuguesa com metodologia de língua segunda no ensino básico - 1. a fase. Bissau: ASDI.

GOMES, A.; PEREIRA, A. (2004), Projecto de apoio ao ensino básico (FASPEBI) - relatório de avaliação. Bissau: ASDI.

HOVENS, M. (1994), A experiência CEEF: uma análise alternativa para o ensino na Guiné-Bissau? Um estudo comparativo dos projetos CEEF, "Português" e o ensino oficial na Guiné-Bissau. Bissau: ASDI.

HOVENS, M. (2002), “Bilingual Education in West Africa: Does It Work?”. International Journal of Bilingual Education and Bilingualism, 5 (5): 249-266. doi:10.1080/13670050208667760

INEE (2010), Minimum Standards for Education: Preparedness, Response, Recovery. New York: INEE.

JANSEN, J. D. (2003), "What education scholars write about curriculum in Namibia and Zimbabwe”, in W. Pinar (Ed.), International handbook of curriculum research. Mahwah: Lawrence Erlbaum Associates, 471-478.

KAMENS, D. H.; BENAVOT, A. (2011). "National, regional and international learning assessments: trends among developing countries, 1960-2009”. Globalisation, Societies and Education, 9 (2), 285-300. doi:10.1080/14767724.2011.577337

KASSAYE, W. (2013), "Curriculum Development and Research in Ethiopia”, in International Handbook of Curriculum Research. New York: Routledge, 161-182.

KHAN, S.; MORGADO, J. C. (2013), "Caminhos desobedientes: pensar criticamente o contexto português de conhecimento". Configurações, 12: 75-88.

KIRK, J. (2007), "Education and fragile states." Globalisation, Societies and Education, 5 (2): 181-200. doi: 10.1080/14767720701425776.

KOUDAWO, F. (1996), "A independência começa na escola. Educação do PAIGC versus educação colonial”, in C. Cardoso and J. Augel (ed.), Guiné-Bissau vinte anos de independência. Desenvolvimento e democracia. Balanço e perspetivas. Bissau: INEP, 67-78.

LE GRANGE, L. (2013), "Curriculum Research in South Africa", in W. F. Pinar (Ed.), International Handbook of Curriculum Research. New York: Routledge, 466-475. 
LOPES, C. (2007). Participação das populações locais no desenvolvimento da educação. Caso de estudo: escolas comunitárias da região de Bafatá, Guiné-bissau (2004-2006), dissertação de mestrado, Instituto Superior de Ciências do Trabalho e da Empresa, Lisboa.

LOPES, L. d. S. L. (2014), A Lei de Bases Do Sistema Educativo da Guiné-Bissau, dissertação de mestrado, Universidade de Aveiro, Aveiro.

MENCCJD (2011), Pedido Financeiro ao Fundo da Parceria Global para a Educação. Retrieved from Bissau: Ministério da Educação Nacional, Ciência, Cultura, Juventude e Desportos.

MENDY, P. K. (2008), “Guinea-Bissau”. In New Encyclopedia of Africa. Detroit: Gale Cengage Learning, vol. 2, 509-516.

MEPIR (2011), Segundo Documento de Estratégia Nacional de Redução da Pobreza. Retrieved from Bissau: Ministério da Economia, do Plano e da Integração Regional.

MO IBRAHIM FOUNDATION (2015), Ibrabim Index of African Governance: Country Insights - Guinea-Bissau. Retrieved from http://static.moibrahimfoundation.org/u/2015 /10/02201358/24_Guinea_Bissau.pdf

MONTEIRO, J. (2005), A Educação na Guiné Bissau: Bases para uma estratégia sectorial renovada. Retrieved from Bissau: Ministério da Educação Nacional, Ciência, Cultura, Juventude e Desportos.

MOREIRA, A. F.; SILVA, T. T. (1995), Currículo, cultura e sociedade (2 ${ }^{\text {a }}$ Ed.). São Paulo: Cortez.

NICOLAI, S. (2009), Opportunities for change: Education innovation and reform during and after conflict. Paris: UNESCO-IIEP.

O'REGAN, D.; THOMPSON, P. (2013), Advancing Stability and Reconciliation in GuineaBissau: Lessons from Africa's First Narco-State. ACSS Special Report No. 2, 58. Retrieved from http://africacenter.org/wp-content/uploads/2013/06/SpecialReport-Guinea-BissauJUN2013-EN.pdf

OBSERVATÓRIO DA LÍNGUA PORTUGUESA (2009), Falantes de Português Lingua Materna. Retrieved from http://www.observatoriolp.com

OECD (2006), “The challenge of capacity development: Working towards good practice”, in DAC Guidelines and Reference Series. Paris: OECD.

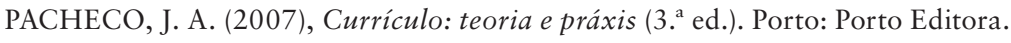

PACHECO, J. A. (2009), "Processos e práticas de educação e formação: Para uma análise da realidade portuguesa em contextos de globalização”. Revista Portuguesa de Educação, 22: 105-143.

PACHECO, J. A. (2011), Discursos e lugares das competências em contextos de educação $e$ formação. Porto: Porto Editora.

PACHECO, J. A. (2014), Educação, Formação e Conhecimento. Porto: Porto Editora.

PACHECO, J. A.; MARQUES, M. (2014), "Governamentalidade curricular: ação dos professores em contextos de avaliação externa”, in M. R. N. S. Oliveira (Ed.), Professor: formação, saberes e problemas. Porto: Porto Editora, 105-135.

PACHECO, J. A.; PEREIRA, N. (2007), "Globalização e identidade no contexto da escola e do currículo. Cadernos de Pesquisa”, 37: 371-398.

PEHRSSON, K. (1996). O direito à educação na Guiné-Bissau: análise genérica dos problemas do sector. Estocolmo: ASDI.

PÉLISSIER, R. (1989a), História da Guiné: portugueses e africanos na Senegâmbia: 1841-1936. Lisboa: Estampa, vol. I.

PÉLISSIER, R. (1989b), História da Guiné: portugueses e africanos na Senegâmbia: 1841-1936. Lisboa: Estampa, vol. II.

RIBEIRO, I. Q. L. A. (2001), Dinâmica do Ensino Popular na Guiné-Bissau. O Caso das Escolas Populares do Bairro de Quelele. Uma Alternativa para o Futuro do Sistema Educativo, dissertação de mestrado, Universidade Aberta, Lisboa. 
ROBERTSON, S. L. (2012), “Researching Global Education Policy: Angles In/Oun/Out...”, in A. Verger, M. Novelli, \& H. K. Altinyelken (Eds.), Global education policy and international development: New agendas, issues and policies. Londres: Bloomsbury Academic, 33-51.

RUDEBECK, L. (2006), "Reading Cabral on democracy". African Identities, 4 (1): 89-98. doi:10.1080/14725840500338581

SANHÁ, C. (2014), Do ensino público ao ensino de iniciativa comunitária (análise do desenvolvimento e impacto das Escolas Comunitárias na Guiné-Bissau e as intervenções das ONGs FEC \& PLAN), dissertação de mestrado, Universidade Federal de Santa Catarina, Florianópolis.

SANTOS, P. d. (1994), Avaliação do projecto português. Retrieved from Bissau: Ministério da Educação Nacional, Ciência, Cultura, Juventude e Desportos.

SILVA, A. E. D. (1997), A independência da Guiné-Bissau e a descolonização portuguesa. Porto: Edições Afrontamento.

SILVA, R. d.; SANTOS, J. G. d.; PACHECO, J. A. (2015), "Crossed looks: globalisations and curriculum in Guinea-Bissau”. Compare: A Journal of Comparative and International Education, 45 (6), 978-999. doi:10.1080/03057925.2015.1013018

SOUDIEN, C. (2010), "What to teach the natives": A historiography of the curriculum dilemma in South Africa, in W. F. Pinar (Ed.), Curriculum Studies in South Africa: Intellectual Histories and Present Circumstances. New York: Palgrave Macmillan, 19-50.

SOUSA, J. S. (2012a), Amílcar Cabral (1924-1973) - Vida e morte de um revolucionário africano (2. a edição ed.). Lisboa: Nova Vega.

SOUSA, J. S. (2012b), Guiné-Bissau: A destruição de um país. Desafios e reflexões para uma nova estratégia nacional. Coimbra: Author.

STEINER-KHAMSI, G. (2012), "Understanding policy borrowing and lending. Building comparative policy studies", in G. Steiner-Khamsi and F. Waldow (ed.), World yearbook of education 2012. Policy borrowing and lending in education. London: Routledge, 5-17.

TEMUDO, M. P. (2008), “From 'People's Struggle' to 'This War of Today': Entanglements of Peace and Conflict in Guinea-Bissau”. Africa: Journal of the International African Institute, 78 (2): 245-263.

TEMUdO, M. P.; ABRANTES, M. (2015), “The Pen and the Plough: Balanta Young Men in Guinea- Bissau”. Development and Change, 46 (3): 464-485. doi:10.1111/dech.12166

TEMUdO, M. P.; ABRANTES, M. B. (2013), "Changing Policies, Shifting Livelihoods: The Fate of Agriculture in Guinea-Bissau". Journal of Agrarian Change, 13 (4): 571-589. doi:10.1111/j.1471-0366.2012.00364.x

TEODORO, A.; ESTRELA, E. (2010), "Curriculum policy in Portugal (1995-2007): global agendas and regional and national reconfigurations”. Journal of Curriculum Studies, 42 (5), 621-647. doi:10.1080/00220271003735728

UNESCO INSTITUTE OF STATISTICS. (2011), UIS statistics in brief. General profile Guinea-Bissau. Retrieved from http://stats.uis.unesco.org/unesco/TableViewer/document. aspx? ReportId=124\&IF_Language $=$ eng $\&$ BR_Country $=6240 \&$ BR_Region $=40540$

UNESCO (2013), Guiné-Bissau - Relatório da Situação do Sistema Educativo. Margens de manobra para o desenvolvimento do sistema educativo numa perspetiva de universalização do Ensino Básico e de redução da pobreza. Dacar: UNESCO.

VARELA, B. (2013), “A educação, o conhecimento e a cultura na práxis de libertação nacional de Amílcar Cabral”. Desafios - Revista da Cátedra Amílcar Cabral, 1: 113-132.

VERGER, A.; NOVELLI, M.; ALTINYELKEN, H. K. (2012), "Global education policy and international development: an introductory framework”, in A. Verger, M. Novelli and H. K. Altinyelken (ed.), Global education policy and international development: New agendas, issues and policies. London: Bloomsbury Academic, 3-31. 
WELDON, G. (2009), A comparative study of the construction of memory and identity in the curriculum in societies emerging from conflict: Rwanda and South Africa, $\mathrm{PhD}$, University of Pretoria, Pretoria.

WILLIAMS, L. (2009), “Globalisation of Education Policy: Its Effects on Developing Countries”, in J. Zajda and V. Rust (ed.), Globalisation, policy and comparative research. Discourses of globalization. Springer Netherlands, 77-92.

Submetido: 28-02-2016

Aceite: 31-05-2016 